\title{
Acute Genotoxic Stress-Induced Senescence in Human Mesenchymal Cells Drives a Unique Composition of Senescence Messaging Secretome (SMS)
}

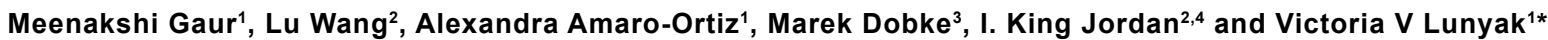

${ }^{1}$ Aelan Cell Technologies, San Francisco, CA

${ }^{2}$ School of Biology, Georgia Institute of Technology, Atlanta, GA

${ }^{3}$ Division of Plastic Surgery, University of California, San Diego, La Jolla, California

${ }^{4}$ PanAmerican Bioinformatics Institute, Cali, Valle del Cauca, Colombia

\begin{abstract}
MSC mediate numerous therapeutic effects by promoting repair directly via differentiation into critical cell types or indirectly through the secretion of a broad spectrum of soluble factors with diverse paracrine activities. However, recent discoveries indicate that MSC are sensitive to endogenous and exogenous stressors and many diseaserelated interventions can result in Therapy-Induced Senescence (TIS) in MSC. Here, we provide a detailed analysis of changes in secretory factors that occur under conditions of bleomycin treatment that triggers genotoxic stressinduced senescence of Human Adipose-Derived Stem Cells (hADSCs). The bleomycin treatment considerably alters the composition of hADSCs secretome. Our data reveal the novel unique composition of Senescence Messaging Secretome (SMS) of hADSCs and suggest that this SMS might critically influence genotoxic drug-based or MSC combinational therapies by imposing interference with tissue homeostasis, metabolism and regeneration in autocrine and paracrine fashion. SMS can compromise MSC-mediated immunological responses and their regenerative potential. Our findings underscore the importance of careful evaluation of stress-induced senescence of adult stem cells in regenerative and combination therapies.
\end{abstract}

Keywords: Senescence messaging secretome (SMS); Genotoxic stress-induced senescence; Bleomycin; Adipose-derived stem cells (ADSCs); Mesenchymal stem cells (MSC); Leptin; ICAM-1; PDGF; Fas Ligand and Immunomodulation

\section{Introduction}

Mesenchymal Stem/ Stromal Cells (MSC) have been currently tested in a significant number of clinical trials, where they exhibit regenerative and repair properties directly through their differentiation into cells of the mesenchymal origin or by modulation of the microenvironment; as well as by interaction with immune cells. The current paradigm is that MSC accomplish many of these therapeutically relevant functions via a paracrine mechanism. A broad spectrum of secretory factors produced by MSC, such as cytokines, chemotactic, ECM remodeling and growth factors, has been reported (as reviewed in [1] and demonstrated in [2-4]).

However, throughout life similar to other adult stem cells, changes in the quantity and quality of MSC might influence tissue homeostasis and metabolism, slow down regeneration rate and promote tissue deterioration. Not surprisingly, age-related deficiencies have also been shown to compromise MSC-mediated immunological responses $[5,6]$. In general, the robust adult stem cell exhaustion is thought to occur due to the process called cellular senescence. Senescence can be inflicted by many intrinsic stimuli, oncogenes, as well as prolonged stress such as drug-induced DNA damage, irradiation, hypoxia, or reactive oxygen species (ROS) [7]. In addition, natural and pathological changes in stem cell microenvironment may trigger senescence [5,8-10]. Despite the exit from the cell cycle, the senescent cells are not simple passive bystanders but rather very active metabolic players. Numerous studies have provided evidence that the senescence-triggered cellular communication circuitry (senescence messaging secretome (SMS) or senescence-associated secretory phenotype (SASP)) is necessary for tissue or organ remodeling and regeneration ([11-14] and reviewed in [7]). Although initially described in fibroblasts [12,15] as a tumor preventive mechanism, SMS is not restricted to the fibroblasts. Importantly, different cell types, including MSC, upon senescence put out different SMS outcomes, and these outcomes vary in accordance to the different triggers that induce senescence and in response to the micro-niche that hosts senescent cells. In a typical cell communication context, a cell secretes a protein that diffuses through the extracellular medium to the neighboring cells before binding to their cell surface receptors. This type of cell-to-cell communication is called paracrine [16]. In addition, a ligand can also bind to receptors on the same cell that secreted it, in cell-autonomous (autocrine) fashion.

Unlike senescence during aging and in age-related diseases (discussed elsewhere) [17,18], programmed senescence during development and regenerative turnover may be restricted to one or few tissues and organs where MSC are residing. Since MSC are more resistant to programmed apoptosis [19] and prefer senescent growth arrest to cell death, one can envision that these cells may be the key drivers that potentiate transient, so-called "beneficial senescence" that ensures successful developmental and regenerative outcomes [20]. Contrary to this, many disease-related interventions can induce Therapy-Induced Senescence (TIS) [21-24]. Senescent MSC can also impose a context-dependent restraint and limitation for numerous therapeutic approaches, one of which is treatments for cancer. While most of the traditional anti-cancer therapies, either generic or targeted, are aimed to induce tumor cell death causing various levels of DNA damage, these therapies might also affect resident MSC. Such resident senescent MSC might exert "bystander" effects inside the tumor

*Corresponding author: Victoria $\mathrm{V}$ Lunyak, Aelan Cell Technologies, San Francisco, CA 94107, USA, Tel: +1(619) 306-1700; E-mail: vlunyak@aelanCT.com

Received July 20, 2017; Accepted August 14, 2017; Published August 20, 2017

Citation: Gaur M, Wang L, Amaro-Ortiz A, Dobke M, King Jordan I, et al. (2017) Acute Genotoxic Stress-Induced Senescence in Human Mesenchymal Cells Drives a Unique Composition of Senescence Messaging Secretome (SMS). J Stem Cell Res Ther 7: 396. doi: 10.4172/2157-7633.1000396

Copyright: ( 2017 Gaur M, et al. This is an open-access article distributed under the terms of the Creative Commons Attribution License, which permits unrestricted use, distribution, and reproduction in any medium, provided the original author and source are credited. 
Citation: Gaur M, Wang L, Amaro-Ortiz A, Dobke M, King Jordan I, et al. (2017) Acute Genotoxic Stress-Induced Senescence in Human Mesenchymal Cells Drives a Unique Composition of Senescence Messaging Secretome (SMS). J Stem Cell Res Ther 7: 396. doi: 10.4172/21577633.1000396

Page 2 of 13

microenvironment through their capacity to lock immunocompetent cells in a quiescent, non-proliferative state $[25,26]$ thus helping tumors to evade immune surveillance. In addition, the "bystander" senescent MSC can promote an environment that supports tumor neovascularization and metastasis through the release of angiogenic, migratory and anti-apoptotic factors [27].

Indeed, senescence by replicative exhaustion or genotoxic stress during ex vivo culturing imposes cell-autonomous and non-cellautonomous restrictions on MSC. These limitations encompass signaling, metabolic and cytoskeletal changes, which ultimately result in the diminished ability of MSC to cope with DNA damage and other stressors. Reportedly these changes result in an inability to maintain the structure and function of chromatin- a process indispensable for the controlled execution of gene transcription program $[10,28,29]$.

Here, we provide a detailed analysis of changes in secretory factors that occur under conditions of genotoxic stress-induced senescence of Human Adipose-derived Stem Cells (hADSCs). SMS composition of hADSCs points to a subset of the factors exclusively secreted by senescent cells that encompass key signaling pathways strongly influencing immunomodulatory properties of MSC, tissue and organs remodeling and paracrine ability to propagate senescent state.

\section{Materials and Methods}

\section{Isolation, culture and characterization of hADSCs}

hADSCs used in this research were obtained from a healthy adult female donor (38 years old) undergoing routine liposuction procedures at the University of California Medical Center, San Diego, CA. Isolation protocol was approved by the local Ethics Committee and performed as previously described [10]. hADSCs used in all experiments were in accordance with the MSC minimal definition criteria set by the International Society for Cellular Therapy [30]. Flow cytometric analysis showed that the adipose tissue derived cells expressed CD29, CD73, CD90 and CD105 but did not express CD11b, CD14, CD19, CD34, CD45, CD80, CD86 and HLA-DR (antibodies from eBioscience, USA). Morphological analysis showed that the cells presented a fibroblast-like morphology, were plastic adherent and capable of differentiation under in vitro conditions using commercially available differentiation medium (Invitrogen, USA), differentiated into adipocytes and osteocytes. The cells were grown in DMEM/F12 medium (Life Technologies). Cumulative Population Doublings (PD) were calculated by summing the population doublings $(\mathrm{PD}=\log (\mathrm{N} / \mathrm{N} 0) \times 3.33$, where $\mathrm{N} 0$ is the number of cells plated in the flask and $\mathrm{N}$ is the number of cells harvested at this passage) across multiple passages as a function of the number of days it was grown in culture as described in Ref. [10].

\section{hADSCs culture and treatments}

hADSCs populations between PD8-PD12 were used as SelfRenewing (SR) cells for performing all experiments in StemPro MSC SFM xeno-free medium containing $10 \%$ supplement (complete xenofree media) (Thermo Fisher Scientific). SEN hADSCs were obtained by treating the hADSCs at PD 9 with $50 \mu \mathrm{g} / \mathrm{ml}$ final concentration of bleomycin diluted from $10 \mathrm{mg} / \mathrm{ml}$ bleomycin stock in complete xeno-free media for $2 \mathrm{hrs}$ at $37^{\circ} \mathrm{C}$ as previously described (in $[27,31]$ and shown schematically in Figure 2A). Following the treatment, the medium was aspirated, the cells were washed twice with PBS and fresh complete xeno-free media was replaced. Cells were maintained in culture for 5 days to achieve senescence and then analyzed.

\section{Senescence-associated $\beta$-galactosidase assay (SA- $\beta$-Gal)}

The $\mathrm{pH}$-dependent senescence-associated $\beta$-galactosidase activity (SA- $\beta-\mathrm{Gal}$ ) assay was performed as described in the manufacturer's kit (BioVision) and previously published $[10,27,29]$. Briefly, the cultured hADSCs were fixed in fixative solution for $15 \mathrm{~min}$ at room temperature, washed twice with PBS and stained with X-Gal containing supplement overnight at $37^{\circ} \mathrm{C}$. Subsequently, the cells were washed twice with PBS, mounted with $70 \%$ glycerol and the images were captured using a microscope (Leica MC170HD Digital Camera, Germany).

\section{Immunofluorescence staining}

Immunostaining of the indicators of senescence $\mathrm{p} 21^{\mathrm{WAF} 1 / \mathrm{Cip} 1}$, p16 and p53BP1, was performed as described previously [10,29]. Additionally, $\gamma \mathrm{H} 2 \mathrm{AX}$ staining was performed to assess DNA damage and BrdU staining was used to quantitate the proliferating cells $[10,29]$ The antibodies used were $\mathrm{p} 21^{\mathrm{WAF} 1 / \mathrm{Cip} 1}(12 \mathrm{D} 1)$, a rabbit monoclonal Alexa Fluor 647 conjugated antibody and BrdU (Bu20a), a mouse monoclonal antibody (Cell Signaling Technology, Danvers, MA), anti-phospho histone $\gamma \mathrm{H} 2 \mathrm{AX}$ (Ser139) mouse monoclonal (Millipore) and 53BP1, a rabbit polyclonal antibody (Bethyl Laboratories, Inc. Montgomery, TX). Anti-CDKN2A/p16INK4a, IL-6, IL-8 and MMP13, rabbit polyclonal antibodies and MMP1 (EP1247Y) and MMP3 (EP1186Y), the rabbit monoclonal antibodies, were purchased from Abcam (Cambridge, MA). Secondary antibodies used were Alexa Fluor 555 donkey antimouse, Alexa Fluor 555 donkey anti-rabbit, and Alexa Fluor 488 donkey anti-rabbit (Thermo Fisher Scientific). 20,000 cells plated on 4-chamber slides in xeno-free medium overnight, were either treated with bleomycin to generate senescent (SEN) hADSCs as described above or left untreated (SR). Nuclear staining was performed with DAPI and the slides were mounted using ProLong anti-fade mounting media (Thermo Fisher Scientific). All imaging was done on Zeiss AxioImager M1 (Zeiss, Germany). Percent positive cell count for BrdU, p21 ${ }^{\text {WAF1/Cip1 }}$ and $\gamma \mathrm{H} 2 \mathrm{AX}$ was performed by counting DAPI-stained nuclei $(\mathrm{n}=200)$ in 3 randomly selected areas and positively stained cells for each antibody were recorded within the selected areas and plotted as the percentage of total DAPI-positive cells.

\section{hADSCs culture in 3-D extracellular matrix (ECM) for collection of trophic factors}

SR or SEN hADSCs were cultured on sterile ECM-like 3D scaffolds in 2-chamber slides following the manufacturer's recommendations. Briefly, ECM containing slides were rinsed twice with PBS and then preincubated with PBS for $15 \mathrm{~min}$ at $37^{\circ} \mathrm{C}$. PBS was aspirated and 10,000 cells were plated in each chamber $\left(2500 / \mathrm{cm}^{2}\right)$ in the xeno-free complete medium. After $24 \mathrm{hrs}$ in culture, $2.8 \mathrm{ml}$ of the fresh xeno-free complete medium was added to the cells. The conditioned medium was collected at $48 \mathrm{hrs}$ post-medium change. For medium only control, medium from wells with no cells was collected at $24 \mathrm{hrs}$. Total Protein measurement was performed in the collected media by Qubit protein assay using Qubit 2.0 Fluorometer (Thermo Fisher Scientific).

\section{Human cytokine array, densitometry data extraction and analysis}

The conditioned medium and composition of xeno-free medium (baseline control) were analyzed by human cytokine array. Assays for secreted human proteins were performed using human cytokine antibody array C2000 (RayBiotech Inc. Norcross, GA) to detect 174 human proteins. All experiments were performed by following manufacturer's instructions. Briefly, the array membranes were blocked for $30 \mathrm{~min}$ at RT and incubated for $2 \mathrm{hrs}$ at RT with $700 \mu \mathrm{l}$ of conditioned medium collected at $48 \mathrm{hrs}$ containing $880 \mu \mathrm{g} / \mathrm{ml}$ (SR hADSCs), 1100 
Citation: Gaur M, Wang L, Amaro-Ortiz A, Dobke M, King Jordan I, et al. (2017) Acute Genotoxic Stress-Induced Senescence in Human Mesenchymal Cells Drives a Unique Composition of Senescence Messaging Secretome (SMS). J Stem Cell Res Ther 7: 396. doi: 10.4172/21577633.1000396

Page 3 of 13

$\mu \mathrm{g} / \mathrm{ml}$ (SEN hADSCs) and $1150 \mu \mathrm{g} / \mathrm{ml}$ (no cell control) total protein. After extensive washing to remove unbound proteins, membranes were incubated with diluted biotin-conjugated antibodies overnight at $37^{\circ} \mathrm{C}$, washed and incubated with HRP-conjugated streptavidin at RT for $2 \mathrm{hrs}$. After repeated washes, each membrane was incubated with chemiluminescence detection buffer for $2 \mathrm{~min}$ at RT. Signals were visualized and digital images were captured for densitometry data collection using Omega Lum C imaging system (Gel Company, San Francisco, CA).

Spot signal densitometry data and raw data extraction was performed for no cell control, SR and SEN hADSCs from densitometry images using LI-COR Image Studio Lite Software (LI-COR Biotechnology, Lincoln, $\mathrm{NE}$ ). Exposure time of $15 \mathrm{~min}$ was selected for imaging all samples, as it provided a high signal/noise ratio. There were 2 experimental replicates for each protein.

\section{Protein expression quantification and statistical analysis}

Raw expression values from blank (negative control), no cell control (complete xeno-free medium only) and experimental groups (SR and SEN) were first used to calculate the relative expression levels. We used two approaches to calculate the relative protein expression levels. The first approach involves a two-step - raw relative expression calculation and $\mathrm{z}$-score transformation. For protein i from sample $\mathrm{j}$, the raw relative expression $d_{i, j}$ were calculated

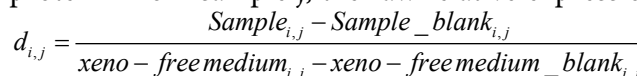

Z-score transformation was then applied to normalize the raw relative expressions $s_{i, j}=\frac{d_{i, j}-A v g_{i, .,}}{S T D E V_{i, .}}$, where $A v g_{i}$ and $S T D E V_{i}$ are the average and the standard deviation of ith protein. The second approach calculates the relative expression of each protein based on the ratio between the sample and complete xeno-free medium. For protein $\mathrm{i}$ from sample $\mathrm{j}$, the relative expression level $r_{i, j}$ were calculated as

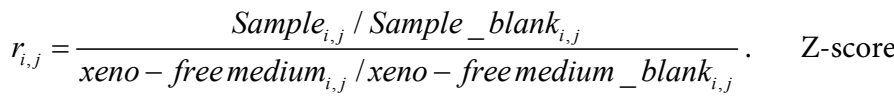

transformation was then applied to normalize the raw relative expressions: $z_{i, j}=\frac{r_{i, j}-A v g_{i, i}}{S T D E V_{i}}$, where $A v g_{i}$ and $S T D E V_{i}$ are the average and the standard deviation of ith protein. A pseudo count of 0.5 has been added to avoid dividing by zero for the relative expression level calculation. We then assessed the statistical significance of changes in protein expression levels between each experimental condition against complete xeno-free medium control, using the two-sided, twosample t-tests. This test yields a P-value for comparing the protein expression levels of each protein between each condition with a complete xeno-free medium. The P-value was then log transformed

as: $N L P=-\log _{10}(P-$ value $)$. For each of the experimental conditions, we calculated average expression levels by taking the mean of the two replicates: $\bar{x}=\left(x_{i}^{\text {replicate }_{1}}+x_{i}^{\text {replicate }_{2}}\right) / 2$. Similarly, we calculated the average expression levels by taking the mean of the two medium-only replicates: $\bar{y}=\left(y_{i}^{\text {replicate }}+y_{i}^{\text {replicate }}\right) / 2$. The average log base 2 fold-change for each condition versus the complete xeno-free medium was then calculated as: $F C_{i}=\log _{2} \frac{\bar{x}_{i}}{\bar{y}}$. For the proteins that have statistically significant changes between the experimental condition and the complete xenofree medium control, we also calculated the paired $\log 2$ fold-changes as:
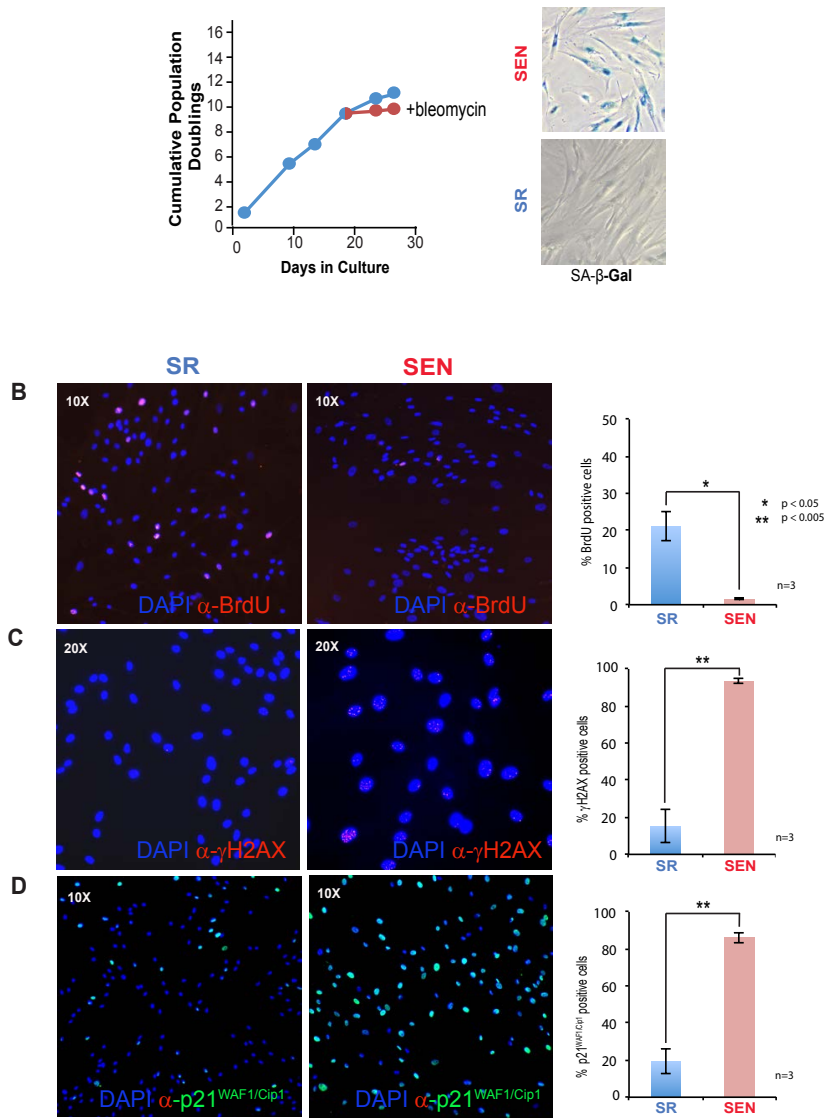

Figure 1: Bleomycin treatment triggers genotoxic stress-induced senescence of hADSCs. A. The growth curve of hADSCs from a 38 years old female donor is represented as cumulative population doubling (PD) over days in culture. Self-renewing linear proliferation stage is shown in blue (SR) and stage when hADSCs enter senescence post-bleomycin treatment is shown in red (SEN). Senescence-associated $\beta$-galactosidase (SA- $\beta$-Gal) staining for SR and SEN population is presented. B,C,D Immunohistological comparison of self-renewing (SR) and bleomycin-induced senescent hADSCs (SEN) following (B) 5'-bromo2'deoxyuridine (BrdU), (C) $\mathrm{YH} 2 \mathrm{AX}$ and (D) p21 $1^{\text {WAF1/Cip1 }}$ staining in self-renewing SR (left) and SEN populations (right) is shown. Nuclei were stained with DAPI (blue) and the image examples at 10X and 20X magnification are presented as indicated. The plots correspond to percent positive cells stained with $\mathrm{BrdU}$, $\mathrm{YH} 2 \mathrm{AX}$ and $\mathrm{p} 21^{\text {WAF } 1 / \mathrm{Cip} 1}$ in 3 randomly selected fields $(n=3)$ at $10 \mathrm{x}$ magnification from 200 DAPI stained cells counted for each. Bars are the standard deviations from the mean. Statistical significance ( $p$-value, depicted as $p$ ) was determined using a two-tailed unpaired Student's t test.

$\log _{2} \frac{x_{i}^{\text {replicate }_{j}}}{y^{\text {replicate }_{j}}}$ where y stands for the relative expression levels in xeno-

free medium, i stands for the experimental condition (i.e. $i=1 \& 2$ ) and $j$ stands for replicates (i.e. $j=1,2$ ).

\section{Proteomic data for SMS factors}

Proteomic data for upregulated SMS secretory factors and analysis was obtained from Ref. [29].

https://www.ncbi.nlm.nih.gov/pmc/articles/PMC5460214/ bin/41514_2017_6_MOESM15_ESM.xlsx

\section{Transcriptome analysis (RNA-seq)}

Gene expression level of upregulated SMS factors was compared to 
Citation: Gaur M, Wang L, Amaro-Ortiz A, Dobke M, King Jordan I, et al. (2017) Acute Genotoxic Stress-Induced Senescence in Human Mesenchymal Cells Drives a Unique Composition of Senescence Messaging Secretome (SMS). J Stem Cell Res Ther 7: 396. doi: 10.4172/21577633.1000396

Page 4 of 13

the transcriptomic RNA levels for SR and SEN hADSCs following the protocols described in Ref. [27]. 100 ng of total RNA of each sample was used to construct libraries for sequencing on Ion Proton (Life Technologies, USA) following the manufacturer's instructions. Sequence reads were mapped to the reference human genome assembly hg19 (GRCh37) using the Torrent Mapping Alignment Program (TMAP, Life Technologies). The quality of the four condition-specific combined RNA-seq runs was evaluated by comparing the expected counts of ERCC spike-in RNA sequences, obtained from the manufacturer's website, against the observed counts of RNA-seq tags that map to the same sequences as described in [27]. Initial gene expression levels were taken as the sum of exon-mapped reads for individual NCBI RefSeq gene models (c), and lowly expressed genes (read counts per million $<1$ ) were removed from subsequent analyses. For each library, individual gene expression levels were normalized using the beta-actin (ACTB) expression levels (cACTB) and the total exon length 1 of each gene. For library $j$, the beta-acting normalization factor sj was calculated as $s_{j}=\frac{\frac{1}{n} \sum_{k=1}^{n} c_{A C T B, k}}{c_{A C T B, j}}$, and the final normalized expression value for gene $\mathrm{i}$ in library $\mathrm{j}$ was calculated as $e_{i, j}=\frac{c_{i, j \times s_{j}}}{l_{i}}$. Differential gene expression analysis between pairs of libraries was performed using the program GFOLD v1.1.3 [32]. GFOLD was chosen based on its demonstrated superior performance in characterizing differentially expressed genes in the absence of replicate data sets. GFOLD analysis yields a score that measures the extent of differential gene expression between conditions; the recommended GFOLD score cut-off of \pm 0.01 was used to define differentially expressed genes here. We employed a combination of twoparameters in order to define differential expression levels between genes: $1)$ the difference in the number reads per kilobase per million mapped reads (dRPKM) and 2) the expression fold-change (FC) level. This approach controls for liabilities of each individual metric; in particular, dRPKM is biased towards highly expressed genes, whereas FC is biased towards lowly expressed genes. In this approach, dRPKM is defined as: $\log _{2} R P K M_{S R} / R P K M_{S E N}$, and FC is defined as: $\log _{2} R P K M_{S R} / R P K M_{S E N}$. For each locus, dRPKM and FC are plotted as a point in two-dimensional Euclidean space, and the Euclidean Distance (D) between the origin and the point is taken to represent the differential expression level. This approach was used separately to evaluate the differential expression of mRNAs [27].

\section{Protein-protein network-based functional analysis}

The proteins that were differentially secreted into the medium by SR or SEN hADSCs at $48 \mathrm{hrs}$ were characterized (Figure 6). The network enrichment approach developed and applied here yields functionspecific sub-networks based on the functional interactions in the STRING database, with edge confidence levels $>0.4$. For each set of functionally annotated proteins, a Steiner tree was built. The Steiner tree is the minimal spanning tree that connects all of the functionally annotated seed proteins by introducing the fewest number of intermediate proteins (i.e. Steiner nodes). The nodes are color coded to show the proteins secreted at $48 \mathrm{hrs}$ by SR (blue) or SEN (red) or both (blue and red) whereas the Steiner nodes are represented in gray (for Ref. [29]).

\section{Results}

\section{Bleomycin treatment triggers genotoxic stress-induced senescence of hADSCs}

Initially we evaluated the induction of acute senescence in hADSCs following the treatments with the genotoxic drug bleomycin as described in Materials and Methods and in [10,29]. hADSCs are multipotent cells of mesenchymal origin from the perivascular compartment. These cells have finite self-renewing (SR hADSCs) properties when passaged ex vivo [10] and undergo genotoxic stress-induced senescence upon treatment with bleomycin which is characterized by the loss of proliferative activity expressed as population doubling (PD) over time (Figure 1A) and bromo-deoxyuridine incorporation (Figure 1B) as expected [27]. The number of BrdU positive cells drops to less than $2 \%$ suggesting the lack of DNA synthesis (Figure 1B). Upon entering senescence, SEN hADSCs enlarge, become more granular with increased lysosomal content characterized by senescence-associated beta-galactosidase (SA$\beta$-Gal) (Figure 1A), and more than 93\% of the cells contained unresolved DNA damage marked by $\gamma \mathrm{H} 2 \mathrm{AX}$ foci (Figure 1C). Bleomycin treatment triggers stress-induced senescence in hADSCs via p21 $1^{\mathrm{WAF} / \mathrm{Cip} 1}$-p53 axis acting upon cell cycle arrest (Figure 1D and Figure 4A and as described in Ref. [7]).

These data demonstrate that exogenous stressor bleomycin triggers a coordinated network of the effector pathways ultimately leading to the senescence-associated cell cycle arrest.

\section{Identification of unique composition of senescence messaging system of hADSCs}

Senescent cells are actively communicating with the neighboring cells within tissues and organs by imposing senescence-specific microenvironment. We then focused on the identification of proteins exclusively present in hADSCs, the Senescence Messaging Secretome (SMS) [33] (also known as Senescence-Associated Secretory Phenotype (SASP) [12] and absent in the secretome of actively self-renewing SR hADSCs (ex vivo). We collected the Conditioned Medium (CM) from SR and SEN hADSCs grown in extracellular matrix (ECM)-like scaffold as shown in cartoon Figure 2A. CM were analyzed by human cytokine antibody array as described in Materials and Methods. Protein arrays were designed to detect 174 proteins specifically selected for their role in signal transduction pathways and intracellular signaling and included: growth factors, cytokines, matrikines, chemokines, their receptors and proteases [7]. The representative example is shown in Figure 2B. Spot signal densitometry data and raw data extraction was performed using LICOR Image Studio Lite Software (LI-COR Biotechnology, Lincoln, NE) (shown in Supplementary Table 1). The protein secretion quantification and statistical significance of the change in the protein secretion was performed using two-sided, two-sample t-test as described in detail in Materials and Methods. The analysis resulted in the identification of proteins that are expressed above the background established as the protein composition of the culturing media containing supplement (no cell control), and we expressed each secreted protein level as the $\log 2$ fold-change relative to a baseline value which was derived from the average signal for that protein across all samples (shown as heat map in Figure 3A).

There are 49 proteins that are present in SR hADSCs CM and 79 proteins in SEN hADSCs CM that show statistically significant level of the secretion above the background present in culturing media (no cell control) (Figure 3B). Out of the 79 proteins present in SEN hADSCs, only 39 proteins are uniquely present in the secretome of SEN hADSCs and represent SMS of hADSCs under the condition of genotoxic stress (Venn diagram in Figure 3B).

There are 40 proteins in common between the conditioned media obtained from SR and SEN cells. Although these proteins are 
Citation: Gaur M, Wang L, Amaro-Ortiz A, Dobke M, King Jordan I, et al. (2017) Acute Genotoxic Stress-Induced Senescence in Human Mesenchymal Cells Drives a Unique Composition of Senescence Messaging Secretome (SMS). J Stem Cell Res Ther 7: 396. doi: 10.4172/21577633.1000396

Page 5 of 13

expressed at higher levels upon senescence of hADSCs, this set of the proteins, in our opinion, is not qualified to represent senescence messaging secretome (SMS) but could be included in senescenceassociated secretory phenotype or SASP. These include Activin A, DR6 (TNFRSF21), IL-8, MPC-1 (CCL2), MPIF, MMP1, MMP3, MMP9 as well as IFN gamma, PECAM1, IP-10 (CXCL10) that were previously implicated to be exclusive properties of the SASP in normal endothelial, epithelial and fibroblast cells and in Table 1 [11,12,14,34-37].

These data demonstrate significant differences in the composition of SASP from the different models of cellular senescence.

\section{Matrix metalloproteinases do not comprise unique composition of SMS of hADSCs}

hADSCs are associated with the vascular stroma where they participate in the maintenance of the blood or lymphatic vessels [38]. In addition, MSC from adipose tissue have shown to be potent immunomodulators. During development angiogenesis and adipogenesis are strongly related, and it comes as no surprise that hADSCs secrete varieties of angiogenic factors [7]. Essential parts of

A
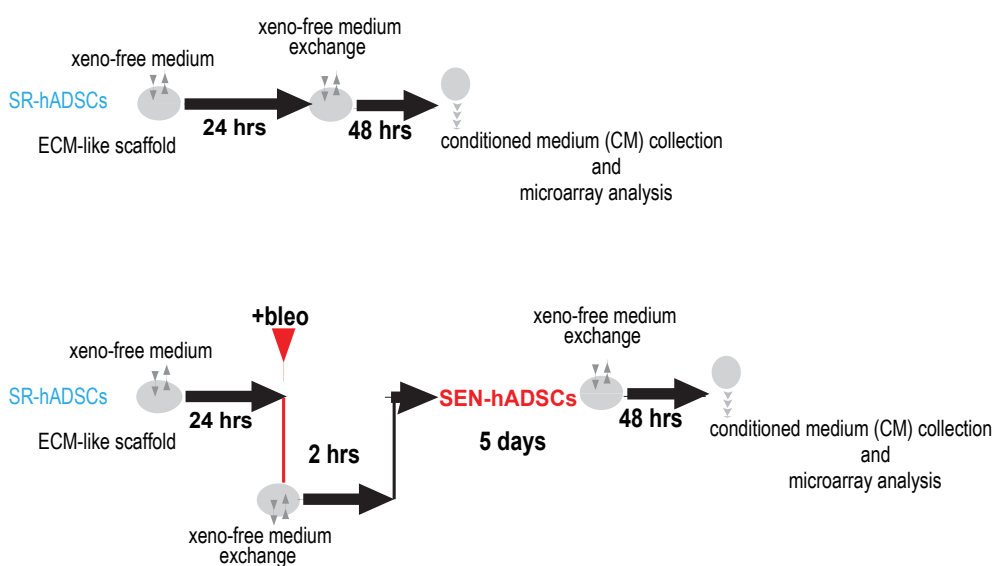

B

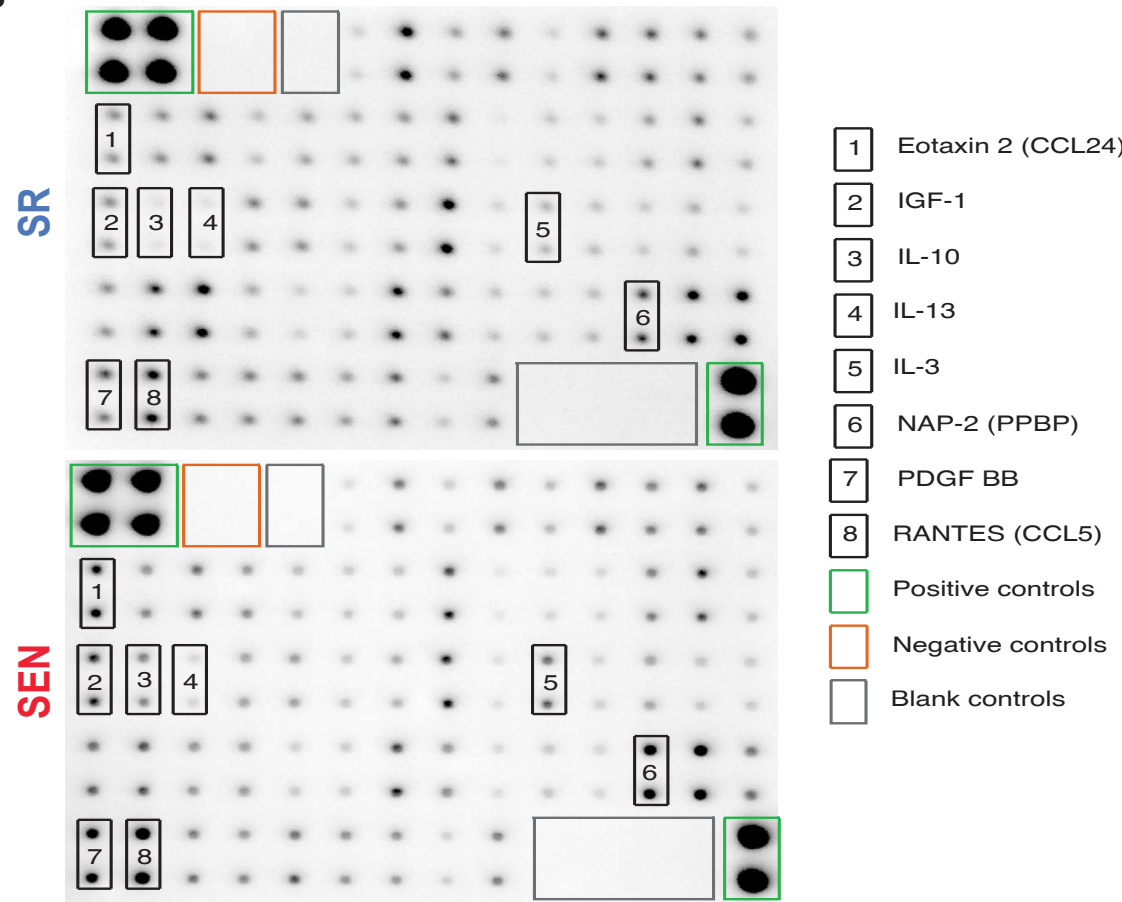

Figure 2: Experiment plan and human cytokine array data collection. A Schematic representation of the microarray experiment is shown. Self- renewing (SR) (top) and bleomycin-induced senescent (SEN) hADSCs (bottom) were cultured on scaffold for collection of conditioned medium at 48 hrs for microarray analysis as described in materials and methods. B A representative example of the cytokine array membrane is shown. The conditioned medium from self- renewing (SR) or bleomycin-induced senescent (SEN) hADSCs collected at 48 hrs was subjected to human cytokine array. Example spots showing upregulated proteins for SEN hADSCs are indicated by black boxes numbered from 1-8 and the corresponding names of the proteins are indicated on the right. Spot signal densitometry data extraction was performed for each cytokine (2 replicates; black boxes), positive controls (6 replicates; green boxes), negative controls (4 replicates; orange boxes) and blank controls (10 replicates; gray boxes) using LI-COR Image Studio Lite Software. 
Citation: Gaur M, Wang L, Amaro-Ortiz A, Dobke M, King Jordan I, et al. (2017) Acute Genotoxic Stress-Induced Senescence in Human Mesenchymal Cells Drives a Unique Composition of Senescence Messaging Secretome (SMS). J Stem Cell Res Ther 7: 396. doi: 10.4172/21577633.1000396

Page 6 of 13

this angiogenic program secreted by ADSCs are metalloproteinases (MMPs) [39,40], which degrade several ECM proteins, including fibronectin, collagen and elastin. MMP3 can also participate in activation of MMP1 and MMP9. Contrary to the observations of mouse and human somatic cells SASPs, genotoxic stress-induced senescence of hADSCs only partially upregulates the secretion of the MMP1, MMP3 and MMP9 and therefore cannot be referred as unique signature ADSC SMS (Figure 4).

However, under the physiological conditions all MMPs are initially produced in a latent form that require activation [41-43], and consequently, all MMPs are inhibited by a group of catalytic inhibitors TIMPs [42]. TIMP2 and TIMP4 are found to be secreted only by SR hADSCs (Figure $3 \mathrm{~B}$ ) and might potentially participate in the inhibition

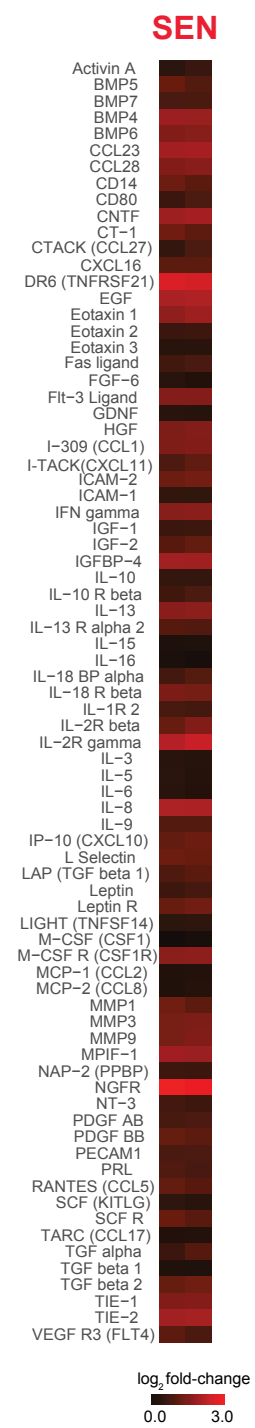

A

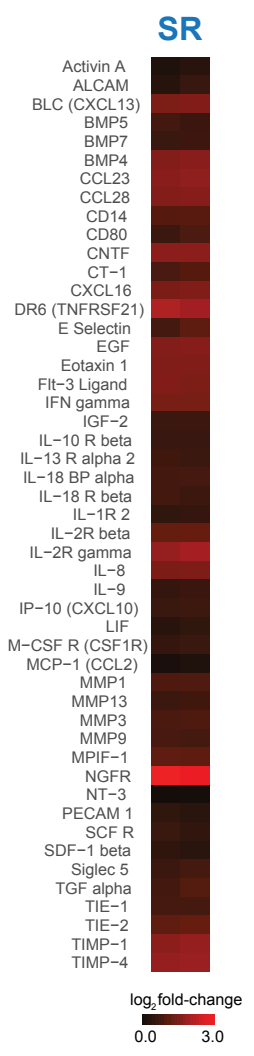

of MMPs function [43].

Our data corroborate the previous observations on detection of the matrix metalloproteinases in conditioned medium of actively self-renewing hADSCs $[39,40]$ and further suggests a caution against including MMP1, MMP3, MMP9 and MMP13 as unique components of SMS or SASP.

\section{Correlation of SMS components with transcription activity of their genes and intracellular protein levels}

Many reports draw a direct correlation between upregulated levels of mRNA, abundance of intracellular proteins and SASP [12,34]. We further deployed the analysis of the previously published transcriptomic [27] and cellular-content proteomic [29] data to establish a correlation
B

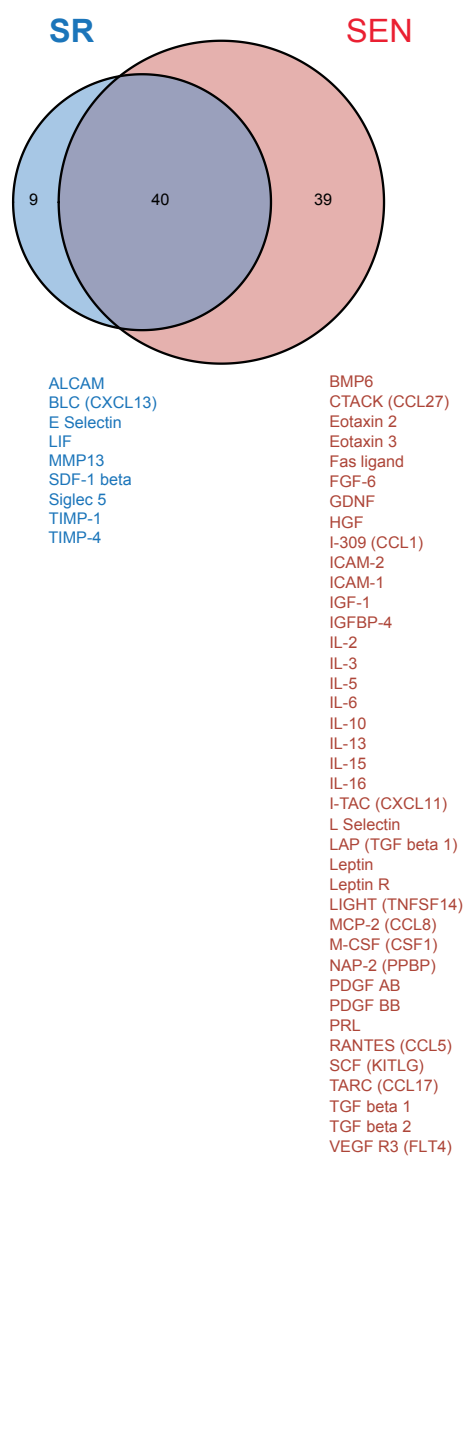

Figure 3: Comparison of secretory protein levels between self-renewing (SR) and senescent (SEN) hADSCs. A Heat map of secreted proteins at 48 hrs from SR and SEN hADSCs is presented. In the heat map shown, the columns correspond to the two replicates and the rows correspond to each of the up-regulated proteins with $p$-value $<0.05$. The color in each cell represents the paired $\log _{2}$ fold-change. Red color represents relatively higher expression levels for a given protein while black color represents expression levels close to the average expression level for a given protein under the condition tested. Protein clusters were sorted based on the hierarchical clustering on the Z-score transformed relative expression values. B Venn Diagram showing the SMS factors present in the conditioned media collected at $48 \mathrm{hrs}$ from SR and SEN hADSCs. The factors that were exclusively secreted by SR (blue) and SEN (red) hADSCs are listed. 
Citation: Gaur M, Wang L, Amaro-Ortiz A, Dobke M, King Jordan I, et al. (2017) Acute Genotoxic Stress-Induced Senescence in Human Mesenchymal Cells Drives a Unique Composition of Senescence Messaging Secretome (SMS). J Stem Cell Res Ther 7: 396. doi: 10.4172/21577633.1000396

with SMS production and transcriptional activity related genes as well as their translation. Overall, three categories can be established for the prominent human SMS factors. First, SMS factors which are upregulated on the transcriptional level and secreted without intracellular protein accumulation. A representative example of CCL5 (RANTES) is shown in Figure 5A. Second, SMS factors which are characterized by decreased transcription upon senescence but featuring robust, statistically significant upregulation on the translational level as noted but increased in intracellular protein accumulation. Examples include IGF-1 and IL-6 (Figure 5B and 5C). The third group encompasses the components of SMS that do not display the upregulation on the transcriptional level and we did not observe any statistically significant changes in the extracellular protein levels in this group. A representative example, ICAM-1, is shown in Figure 5D.

Overall our data demonstrate no direct regulatory relationship between transcription of the SMS gene and secretion of these proteins. We did not observe a universal coordinated increase of expression in SMS factors on the gene transcription level upon induction of genotoxic stress-induced senescence in hADSCs, as previously described for mouse and human somatic cells [34], suggesting that induction of the secretion of unique protein components of SMS in human adult stem cells might be more complex than previously anticipated.

\section{Network-based functional enrichment analysis of secreted proteins}

Since several secreted proteins are co-expressed at different levels upon SR and SEN in hADSCs (Figures 3 and 4), one might expect that they jointly regulate distinct molecular pathways not only during SR and SEN stages but also co-regulating the same pathways. With this in mind, we developed a network-based functional enrichment analysis method to visually elucidate the potential roles of, and interactions among, integrated molecular networks of potentially functionally related genes secreted in SR and SEN hADSCs (see Materials and Methods for details on the network analysis).

The proteins secreted in SR and SEN were interrogated based on their functional annotations and used to seed the network analysis [44]. To identify functional interactions among the corresponding secreted protein, we then linked these genes in a network by edges that represent known relationships between the genes based on a variety of functional interactions, such as physical protein-protein interactions,

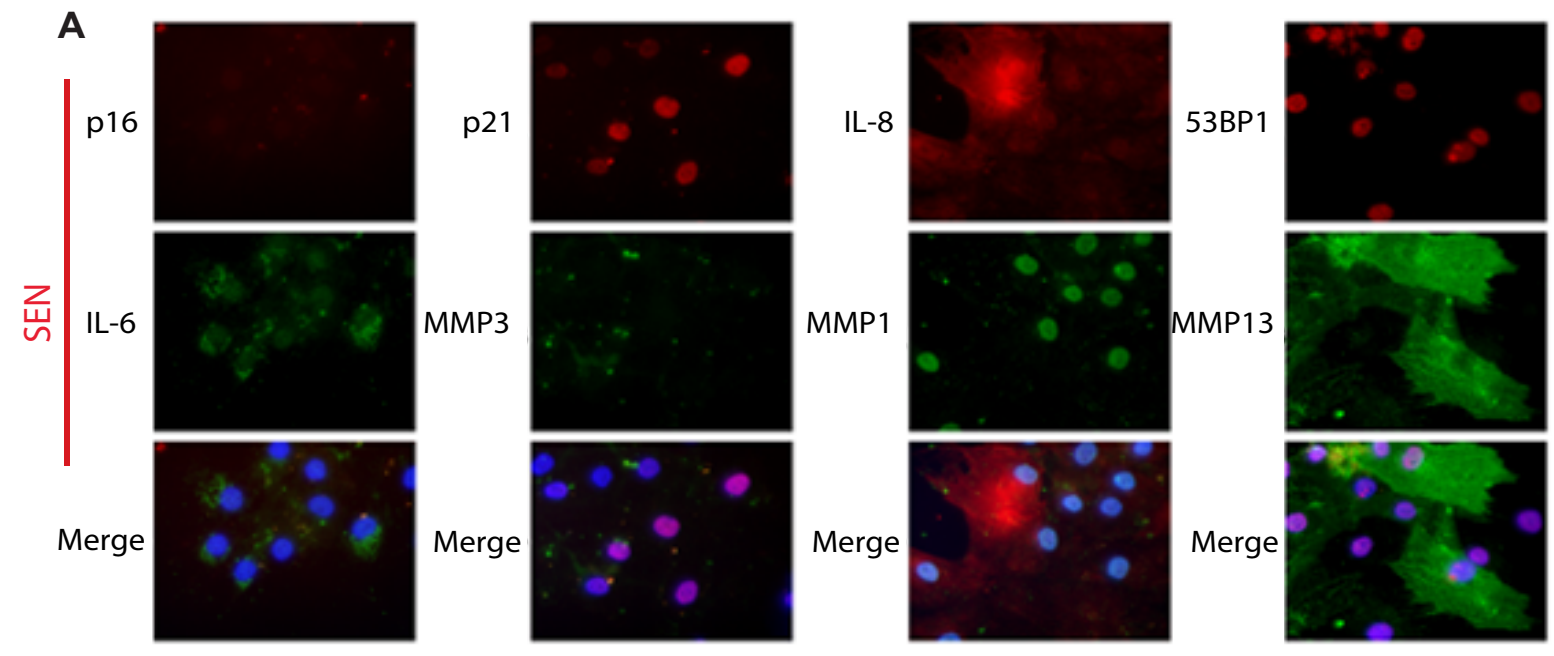

B

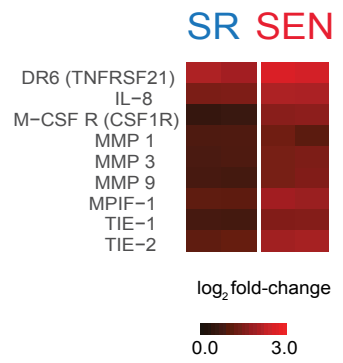

Figure 4: Self-renewing (SR) and senescent (SEN) hADSCs express matrix metalloproteinases. A Immunofluorescence staining of senescent (SEN) hADSCs showing expression of p16, p21, IL-8 and 53BP1 (top) and co-localization with angiogenic factors IL-6, MMP3, MMP1 and MMP13 (middle) respectively. The bottom row represents the merged images. B Heat map showing a comparison of the secretory matrix metalloproteinases levels between self-renewing (SR) and senescent (SEN) hADSCs at $48 \mathrm{hrs}$. The columns are corresponding to the two experimental replicates and the rows represent the up-regulated proteins with $p$-value $<0.05$. The color in each cell represents the paired $\log _{2}$ fold-change. Red color represents relatively higher expression levels for a given protein while black color represents expression levels close to the average expression level for a given protein under the condition tested. Protein clusters were sorted based on the hierarchical clustering on the z-score transformed relative expression values. 
Citation: Gaur M, Wang L, Amaro-Ortiz A, Dobke M, King Jordan I, et al. (2017) Acute Genotoxic Stress-Induced Senescence in Human Mesenchymal Cells Drives a Unique Composition of Senescence Messaging Secretome (SMS). J Stem Cell Res Ther 7: 396. doi: 10.4172/21577633.1000396

Page 8 of 13

gene co-expression and text mining co-relationships. Genes that do not have any direct known relationships of this kind are transitively linked via the minimum number of possible intermediate gene nodes, some of which are not a component of the secretome. The intermediate nodes, so-called Steiner nodes are shown in gray in Figure 6 and described in Materials and Methods.

\section{A CCL5}
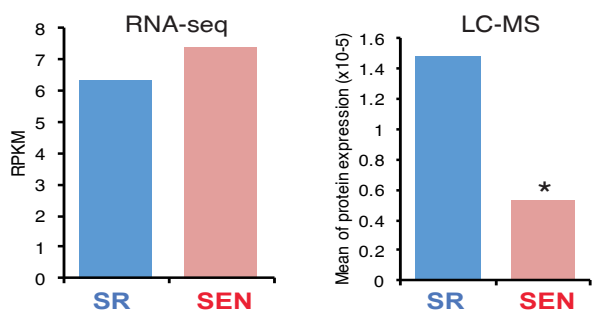

B
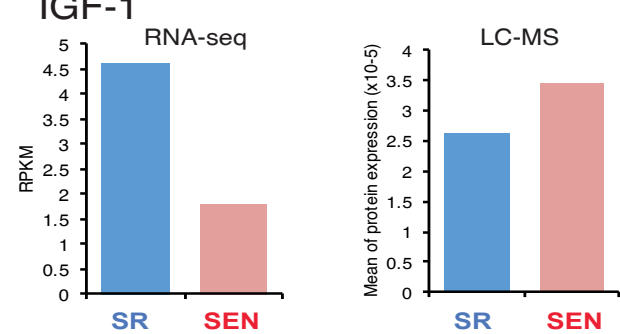

C IL-6
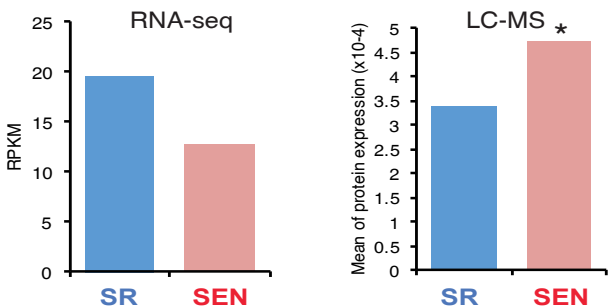

D ICAM-1
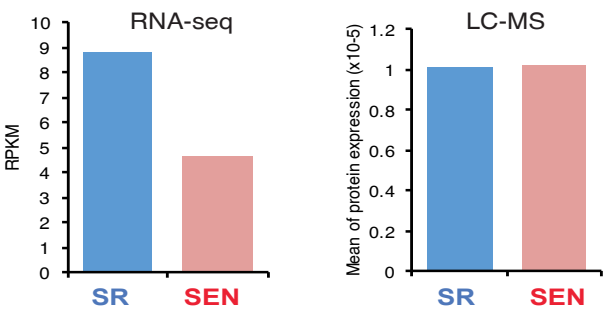

${ }^{*} \mathrm{p}<0.05$

Figure 5: Correlation of SMS components at transcriptomic and proteomic levels. A,B,C,D The plots are representative examples of SMS factors analyzed from SR (blue) or SEN (red) hADSCs. The SMS proteins comprised of 3 categories. A Proteins upregulated at transcriptomic level but low intracellular protein level was detected (CCL5). B,C Decreased transcription but increased accumulation of protein was detected under senescence (IGF-1 and IL-6). D No significant changes in transcriptomic or proteomic levels (ICAM-1). Statistical significance ( $p$-values, depicted as $p$ ) was determined using a two-tailed unpaired Student's t test (significance $<0.05$ ).
The network functional enrichment analysis resulted in clearly defined function-specific sub-networks, along with the interrelationships between these two conditions SR and SEN (Figure 6). The coalescence of proteins into discrete sub-networks supports their close functional relationships and tight interactions. Our analysis indicates several central nodules of these sub-networks that are regulated exclusively by components of the SMS, such as IGF-1, EGFR, VEGFR, IL-2, IL-4, IL-10 and ICAM-1.

Considering that we started with a very small number of the secreted proteins, the large network of functionally related clustered genes identified by this method is surprising but immediately apparent. These data indicate that SMS components act upon already established by self-replicating hADSCs secretory molecular pathways, and represent distinct central nodules that can be subjected to precision targeting in the therapeutic interventions.

\section{SMS composition conservation in the different models}

It was previously reported that mouse and human SASPs (SMS) showed substantial qualitative and quantitative conservation for the cell cultures under the physiological conditions [34]. To better understand the SMS and its conservation among different models of stress-induced senescence we compared previously reported SASP [11,12,14,35,36] and SIR [37] compositions to the composition of unique SMS of hADSCs (Table 1). Out of 70 proteins representing SASP composition in normal endothelial, epithelial and fibroblast cells [18] only 13 proteins BMP6, CCL1, CCL8, Eotaxin 3, FAS, HGF, ICAM-1, IGF-1, IL-6, IL-13, IL-15, NAP-2 and TGF- $\beta 1$ are in common with hADSCs SMS. There are only two proteins ICAM-1 and IGFBP-4 out of 59 reported SIR components [18] in common with SMS of hADSCs.

Our data indicate that there is no large scale overlap in the components of the SMS (SASP/SIR) derived from different models of senescence and suggests that these differences might, indeed, impact the consequences of the paracrine or systemic influence of senescent cells within organ and tissues.

\section{Discussion}

hADSCs have shown great potential in numerous pre-clinical and clinical studies for a wide variety of pathological conditions and diseases [7], leaving physicians and stem cell researchers interested in understanding the mechanistic underpinnings responsible for successful outcomes of cell therapies. These mechanisms are not yet fully understood along with the lack of a comprehensive picture related to the physiological role of the native MSC in the processes of regeneration, and tissue and organ homeostasis. In light of their physiological functions and high therapeutic potential in treatments of numerous diseases such as cancer, tissue injury, and autoimmunity; the understanding of MSC's response to genotoxic insults as well as natural and/or exogenous stressors that can induce senescence is of great interest [7,21-23]. The drawbacks of MSC senescence in tissue and organ homeostasis could be twofold: 1) a loss of tissue repair capacity due to diminishing self-renewal (pool preservation impact) and differentiation (tissue imbalance) caused by the cell cycle arrest; 2 ) a microenvironment modulation by senescent MSC due to secretion of pro-inflammatory and matrix-degrading molecules, which, if escalated, might have a significant local or systemic impact on overall organism homeostasis. The open question is whether the genotoxic stressors such as bleomycin can influence hADSCs senescence-associated secretory broadcast. Our study was aimed to investigate the changes in the 
Citation: Gaur M, Wang L, Amaro-Ortiz A, Dobke M, King Jordan I, et al. (2017) Acute Genotoxic Stress-Induced Senescence in Human Mesenchymal Cells Drives a Unique Composition of Senescence Messaging Secretome (SMS). J Stem Cell Res Ther 7: 396. doi: 10.4172/21577633.1000396

Page 9 of 13

\begin{tabular}{|c|c|c|c|c|c|}
\hline \multirow[b]{2}{*}{ SMS } & \multirow[b]{2}{*}{ SIR } & \multirow[b]{2}{*}{ SMS } & \multicolumn{3}{|c|}{ Table continued: } \\
\hline & & & SMS & SIR & SMS \\
\hline Replicative, Genotoxic and OIS & Genotoxic & Genotoxic & Replicative, Genotoxic and OIS & Genotoxic & Genotoxic \\
\hline [18] & [18] & & [18] & [18] & \\
\hline BMP6 & & BMP6 & GMCSF & IL-1RN & \\
\hline CCL1 & & CCL1 & Gmfg & ISG15 & \\
\hline CCL8 & & CCL8 & Heregulin & Itga2 & \\
\hline Eotaxin 3 & & Eotaxin 3 & ICAM-3 & Lass3 & \\
\hline FAS & & FAS & IGFBP-1 & Lpo & \\
\hline HGF & & HGF & IGFBP-2 & Mapk11 & \\
\hline ICAM-1 & ICAM-1 & ICAM-1 & IGFBP-6 & Mif & \\
\hline \multirow[t]{2}{*}{ IGF-1 } & & IGF-1 & IGFF-2R & Msx2 & \\
\hline & IGFBP-4 & IGFBP-4 & IL-1a & MX1 & \\
\hline IL-6 & & IL-6 & IL-1b & MX2 & \\
\hline IL-13 & & IL-13 & IL-7 & NXN & \\
\hline IL-15 & & IL-15 & Inhibin A & OAS2 & \\
\hline NAP-2 & & NAP-2 & IQGAP2 & OAS3 & \\
\hline TGFb1 & & TGFb1 & Itga2 & OLR1 & \\
\hline Activin A & Atf5 & CCL5 & Itpka & Phlda1 & \\
\hline Amphiregulin & Ccdc33 & CCL17 & Jun & Pla2g2a & \\
\hline Angiogenin & CD9 & CCL27 & Mif & Pla2g2f & \\
\hline Axl & CD14 & CSF1 & MMP1 & Prss22 & \\
\hline bFGF & CD276 & CXCL11 & MMP2 & PTGES & \\
\hline BMP2 & CD40 & Eotaxin 2 & MMP3 & Rel & \\
\hline CCL2 & Cpa2 & FGF-6 & MMP10 & Runx1 & \\
\hline CCL3 & CXCL1 & FLT4 & Osteoprotegerin & SLC7a11 & \\
\hline CCL7 & CXCL3 & GDNF & PAl1 & Sox17 & \\
\hline CCL13 & CXCL5 & ICAM-2 & Pecam1 & Sox4 & \\
\hline CCL16 & CXCL9 & IL-2 & PIGF & Tirap & \\
\hline CD9 & CXCL10 & IL-3 & PTGES & TLR1 & \\
\hline CD55 & ETV5 & IL-5 & RPS6ka5 & TLR2 & \\
\hline CSF2 & Faim2 & IL-10 & Timp2 & TNFRSF19 & \\
\hline CSF2RB & Fam129a & IL-16 & UPAR & TNFRSF8 & \\
\hline CXCL1 & Hamp & KITLG & VEGFa & Tnip2 & \\
\hline CXCL5 & Hif3a & L-Selectin & VEGFc & USP18 & \\
\hline EGFR & IFIT1 & LAP & Wnt2 & Xaf1 & \\
\hline ENA78 & IFIT2 & Leptin & & & \\
\hline Epiregulin & IFIT3 & Leptin R & & & \\
\hline Ets2 & IFITM3 & PDGF AB & & & \\
\hline FGF7 & IGF2BP1 & PDGF BB & & & \\
\hline GCP2 & IGFBP1 & PRL & & & \\
\hline GDF 15 & IL-1a & TGFb2 & & & \\
\hline GEM & IL-1f9 & TNFSF14 & & & \\
\hline
\end{tabular}

Table 1: SMS composition in different models of senescence. Comparison of previously reported SMS [18] to SMS of adipose-derived mesenchymal stem cells induced to acute senescence by genotoxic stress. Column one lists SMS of normal endothelial, epithelial and fibroblast cells reported in $[11,12,14,35,36]$. Column two shows the Senescence-associated Inflammatory Responses (SIR) from the intestinal cells [37]. The third column from the left-SMS from the adipose-derived mesenchymal stem cells induced to senescence by bleomycin. Common proteins are highlighted in bold red.

secretory properties of hADSCs induced by this treatment.

In this manuscript we describe the composition of soluble factors that are uniquely produced by hADSCs under conditions of genotoxic stress-induced senescence, referred in this manuscript as Senescence Messaging Secretome (SMS). We not only disclose a unique composition of SMS broadcast from hADSCs and remarkable interconnectivity of its paracrine circuit (functional network) but also suggest multifaceted consequences of such broadcast altered by chemotherapeutic drug secretory output of hADSCs on the tissue and organs microenvironment. The results of our investigations imply that this SMS output can interfere with therapeutic interventions on several levels, and can act not only locally, but also systemically.

First, is an ability of reported senescent secretome component to influence ECM remodeling. The increase in secretion of MMP1, MMP3 and MMP9 and absence of their inhibitors TIMPs might directly trigger ECM degradation [41-43,45]. In hADSCs SMS, the presence of mitogenic growth factors such as transforming growth factors (TGF $\beta 1$ and $\beta 2$ ), basic Fibroblast Growth Factor (FGF-6), Hepatocyte Growth Factor (HGF), Vascular Endothelial Growth Factor (VEGF), Insulinlike Growth Factor -1 (IGF-1), and Platelet-derived Growth Factors (PDGF) as well as number of cytokines (shown in Figure 3) suggests that the senescence-triggered cellular communication could result in an increase in fibroblasts, keratinocytes, epithelial and endothelial cell division, migration or differentiation, thus triggering ECM remodeling [46-50].

Second, several factors of hADSCs SMS can have a substantial 
Citation: Gaur M, Wang L, Amaro-Ortiz A, Dobke M, King Jordan I, et al. (2017) Acute Genotoxic Stress-Induced Senescence in Human Mesenchymal Cells Drives a Unique Composition of Senescence Messaging Secretome (SMS). J Stem Cell Res Ther 7: 396. doi: 10.4172/21577633.1000396

\section{Protein-protein network}

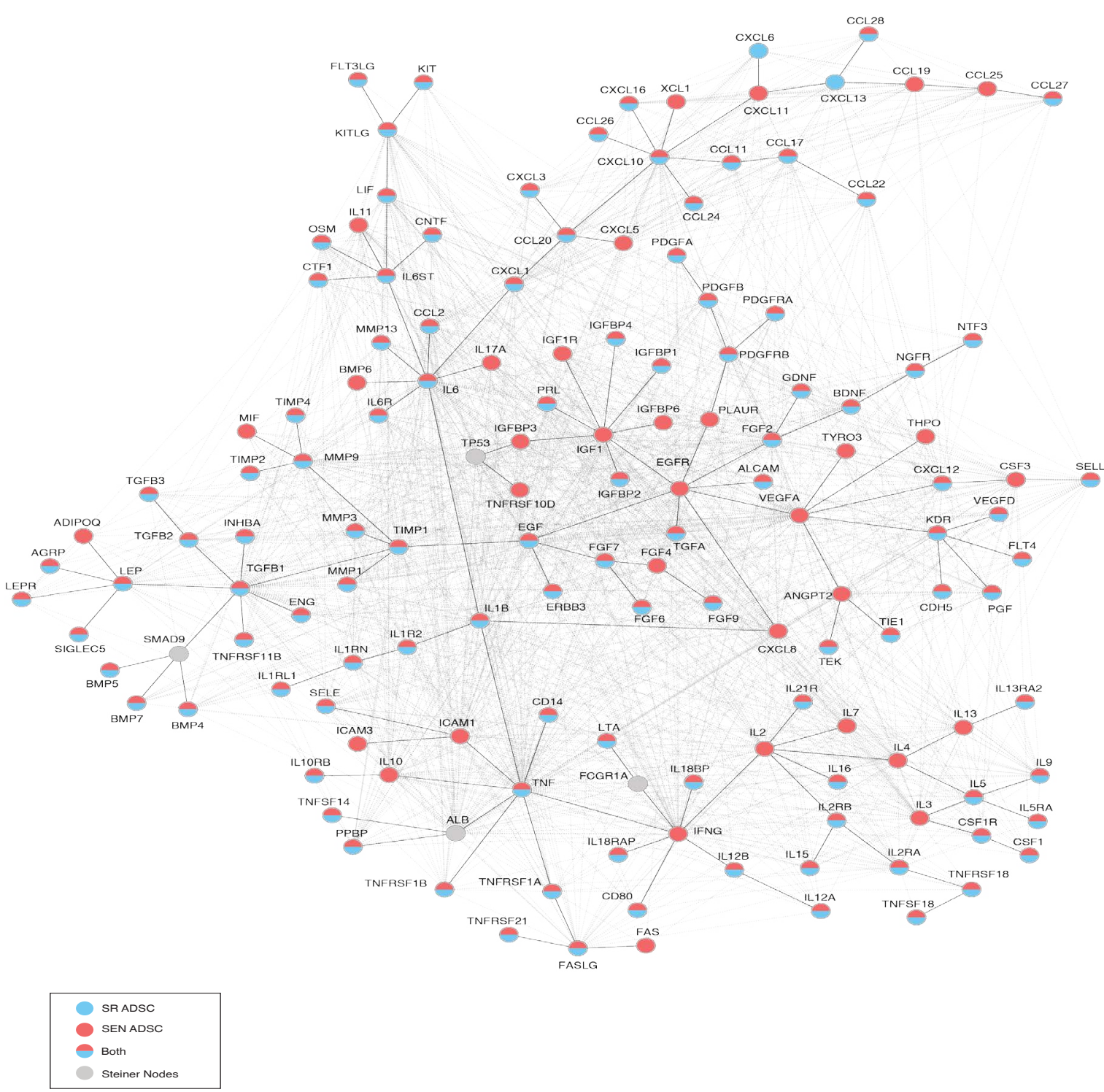

Figure 6: Protein-protein interaction network analyzed by STRING software. Functional relationships of SMS proteins analyzed from SR and SEN hADSCs at 48 hrs is shown. The association of proteins into discrete sub-networks supports their close functional relationships and tight interactions in the Steiner tree. Nodes are color coded to show secreted proteins by SR (blue) or SEN (red) or both (blue and red) at 48 hrs whereas the Steiner nodes are represented in gray.

impact on immune regulations and provide immunomodulation for the components of innate or adaptive (or both) immune system. There is overwhelming evidence that MSC in their natural environment secrete both pro-and anti-inflammatory cytokines as well as their antagonists [51]. Such secretions triggered cellular communication circuitry and have been shown to provide sophisticated signaling guidance to many immune cells, including T cells, natural killer cells, B cells, monocytes, macrophages and dendritic cells [25,47,52-54]. hADSCs senescence considerably alters the composition of SMS and this alteration might result in an impairment or enhancement of the immunomodulatory properties. For instance, leptin functions as a modulator of both innate and adaptive immunity $[55,56]$. This protein affects innate immunity by regulating the function and immune activity of mast cells by increasing their survival rate and migration. In adaptive immunity, leptin has been shown to promote generation and survival of $\mathrm{T}$ cells by reducing their apoptosis. Leptin also promotes increased expression and secretion of interferon- $\gamma($ IFN- $\gamma)$, thus stimulating the Th17 development and responses. However, leptin acts as a negative effector of the expansion human regulatory $\mathrm{T}$ cells (Treg) [57]. These observations, together with the ability of leptin to activate secretion of TNF- $\alpha$, IL- 6 and IL10 in B cells suggests that this prominent component of ADSC SMS functions as a potent proinflammatory mediator relevant to numerous immunological outcomes in development and disease. Another example is the intracellular adhesion molecule-1 (ICAM-1), which is among the unique secretory output of SEN ADSCs. ICAM-1 is a member of the immunoglobulin superfamily [58] and its membrane-bound isoform is 
Citation: Gaur M, Wang L, Amaro-Ortiz A, Dobke M, King Jordan I, et al. (2017) Acute Genotoxic Stress-Induced Senescence in Human Mesenchymal Cells Drives a Unique Composition of Senescence Messaging Secretome (SMS). J Stem Cell Res Ther 7: 396. doi: 10.4172/21577633.1000396

widely known for its functions in adhesion and trafficking of immune cells across the blood vessels during all inflammatory responses [5860]. ICAM-1 is expressed on a wide range of immune cells such as monocyte-macrophage lineage cells, B-lymphocytes, plasma cells and on activated and memory $\mathrm{T}$ cells where it functions to mediate immune synapses thereby initiating the signaling pathways for the major histocompatibility complex (MHC-I and MHC-II) molecules. However, it also exists in the soluble form, sICAM-1. Soluble ICAM1 is capable of binding to Lymphocyte Function associated Antigen-1 (LFA-1) molecules, and production of sICAM-1 is therefore thought to have immunomodulatory consequences. The experiments in sICAM transgenic animal models indicate that soluble ICAM interferes with ICAM-1 mediated cell-cell interactions and produces immunesuppressant effects [61] suggesting its potential role in the SMSmediated regulation of immunity.

Third, is the ability of senescent cells to activate self-amplifying SMS network in which SMS secreted factors can reinforce and propagate senescence in an autocrine and paracrine manner [7,13,36] setting a stage for cross-talk between senescent cells and their environment and depicted in Figure 7. For example, it has been demonstrated that prominent SMS component observed in our studies NAP-2 (PPBP) and leptin can act synergistically and promote/reinforce senescence in MSC through the enhancement of the Pi3K/AKT signaling pathway and are involved in the pathogenesis of systemic lupus erythematosus (SLE) (Figure 7, left side) [62]. In addition, several soluble factors such as IGFBP-7 [63], PAI-1 [64], IL-6 and CXCR2-binding chemokines (such as IL-8 or GROa) [11] can reinforce senescence. It was also demonstrated that senescence could extend the "footprint" of growth arrest to normal or pre-malignant neighboring cells (Figure 7, right side). The paracrine senescence can be transmitted by a number of the factors including ligands of TGF $\gamma$ and BMP branches that mediate changes in the transcriptional program through the SMAD family members SMAD2/3 and SMAD1/5 [36]. These ligands include TGF $\beta 1$, BMP6, BMP2, Inhibin A, VEGF, MCP-1 (CCL2), CCL20 and GDF15 [36] and are abundantly present in the secretory output of the hADSCs. Similarly, then another prominent component of hADSCs SMS, insulin-like growth factor binding protein 4 (IGFBP-4), a key regulator of the IGF signaling pathway, has shown to promote senescence in the early passages of self-renewing MSC [65]. However, the levels of soluble factors, gradients of their concentration, as well as an ability of different cell types to read such transmitted SMS would influence whether or not cells undergo paracrine senescence in vivo, reviewed in detail [7].

Remarkably, detailed analysis of the different SMS revealed that broadcast from senescent cells is not "one-size-fits-all". Important to the subject of this discussion is a notion that one of the key issues in autocrine and paracrine cell communication is related to the time and quantitates of secreted signals, as well as a length of the exposure to the signal [66]. The SMS as any communication system is not a static but rather a well-controlled and dynamic process. It is highly probable that SMS signals vary with time and include not only an autocrine feedback loop but also an ability of senescence cells to "listen" to the environment and respond to it by adjusting or spatially restricting SMS secretory output (schematically shown in Figure 7 and discussed in details [33].

Taken together these observations suggest that SMS could exert more complex physiological roles in the context of tissue homeostasis than are currently understood. The complexity of hADSCs SMS may provide a biochemical framework for understanding several intriguing questions related to the previously reported quite contradictory
Senescence Messaging Secretome (SMS)/SASP

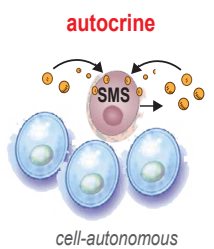

Senescence

Reinforcement

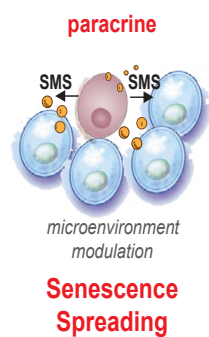

Spreading

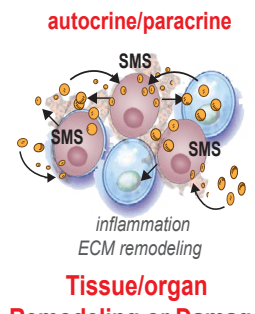

Remodeling or Damage
Figure 7: Active communication of the senescent cells with their microenvironment through the SMS. Senescent cells secrete a plethora of factors as a part of senescence messaging secretome (SMS). This factors to can reinforce the establishment of the senescence in the cell-of-origin in autocrine manner (left panel). The senescent cells can also trigger the microenvironment modulation by acting upon extracellular matrix and on the neighboring cells via secretion of wide array of the growth factors, cytokines, chemokines and receptor decoys (center). SMS also could lead to establishment of senescence in neighboring cells in a paracrine manner (right panel). Increasing "senescence footprint" in tissue and organs can lead to further amplification of the SMS and might enhance the transformation of tumor-predisposed cells.

effects of MSC on tumor progression, where both tumor-promoting and tumor-suppressive responses were reported [67]. Our data might provide a plausible explanation and suggest a testable hypothesis for careful investigation of the interconnected relationship between senescent MSC (naïve or therapeutically-delivered) and tumor cells to resolve this controversy. The impact of other chemotherapy treatments on the secretory behavior of MSC and their function should be carefully considered with respect to the risk of interference with therapeutic endpoints and developing the adverse reactions. Moreover, the predisposition of MSC to stress-related senescence should be carefully evaluated in regenerative approaches that involve ex vivo cell expansion, prolonged stem cell storage (cryopreservation) and genetic and/or chemical manipulation.

Our data also highlight the plausible therapeutic potential of the ex vivo bleomycin-treated hADSCs and it's SMS. While it might represent an undesirable effect in some strategies, for instance upon bleomycin-containing chemotherapies, the described hADSCs SMS may be used as therapeutics and be beneficial for the removal of excessive depositions of collagen desired to counteract connective tissues disorders and fibrosis.

\section{Funding}

This work was supported by Aelan Cell Technologies and an NIH grant (5R21AG043921-02) to V.V.L.

\section{Conflict of Interest}

The authors declare no conflict of interest.

\section{Author Contributions}

V.V.L. and M.G. designed the experiments, assembled the data, wrote the paper and generated the figures. M.G. and A.A.O. performed the experiments. L.W. and I.K.J. performed bioinformatics analysis and generated figures. All authors helped with the manuscript preparation.

\section{References}

1. Gaur M, Dobke M, Lunyak VV (2017) Mesenchymal Stem Cells from Adipose Tissue in Clinical Applications for Dermatological Indications and Skin Aging. 
Citation: Gaur M, Wang L, Amaro-Ortiz A, Dobke M, King Jordan I, et al. (2017) Acute Genotoxic Stress-Induced Senescence in Human Mesenchymal Cells Drives a Unique Composition of Senescence Messaging Secretome (SMS). J Stem Cell Res Ther 7: 396. doi: 10.4172/21577633.1000396

Page 12 of 13

Int J Mol Sci 18: 208. [PubMed]

2. Ponte AL, Marais E, Gallay N, Langonne A, Delorme B, et al. (2007) The in vitro migration capacity of human bone marrow mesenchymal stem cells: comparison of chemokine and growth factor chemotactic activities. Stem Cells 25: 1737-1745. [PubMed]

3. Eggenhofer E, Luk F, Dahlke MH, Hoogduijn MJ (2014) The life and fate of mesenchymal stem cells. Front Immunol 5: 148. [PubMed]

4. Attar-Schneider O, Zismanov V, Drucker L, Gottfried M (2016) Secretome of human bone marrow mesenchymal stem cells: an emerging player in lung cancer progression and mechanisms of translation initiation. Tumour Biol 37 4755-4765. [PubMed]

5. Signer RA, Morrison SJ (2013) Mechanisms that regulate stem cell aging and life span. Cell Stem Cell 12:152-165. [PubMed]

6. Liu R, Chang W, Wei H, Zhang K (2016) Comparison of the Biological Characteristics of Mesenchymal Stem Cells Derived from Bone Marrow and Skin. Stem Cells Int 2016: 3658798

7. Lunyak VV, Gaur M, Amaro-Ortiz A (2017) Mesenchymal Stem Cells Secretory Responses: Senescence-Messaging System and Immunomodulation Perspective. Frontiers in Genetics Under Review.

8. Rao MS, Mattson MP (2001) Stem cells and aging: expanding the possibilities. Mech Ageing Dev 122: 713-734. [PubMed]

9. Janzen V, Forkert R, Fleming HE, Saito Y, Waring MT, et al. (2006) Stemcell ageing modified by the cyclin-dependent kinase inhibitor p16INK4a. Nature 443: 421-426. [PubMed]

10. Wang J, Geesman GJ, Hostikka SL, Atallah M, Blackwell B, et al. (2011) Inhibition of activated pericentromeric SINE/Alu repeat transcription in senescent human adult stem cells reinstates self-renewal. Cell Cycle 10: 30163030. [PubMed]

11. Acosta JC, O'Loghlen A, Banito A, Guijarro MV, Augert A, et al. (2008) Chemokine signaling via the CXCR2 receptor reinforces senescence. Cell 133 1006-1018. [PubMed]

12. Coppe JP, Patil CK, Rodier F, Sun Y, Munoz DP, et al. (2008) Senescenceassociated secretory phenotypes reveal cell-nonautonomous functions of oncogenic RAS and the p53 tumor suppressor. PLoS Biol 6: 2853-2868. [PubMed]

13. Kuilman T, Michaloglou C, Mooi WJ, Peeper DS (2010) The essence of senescence. Genes Dev 24: 2463-2479. [PubMed]

14. Kuilman T, Michaloglou C, Vredeveld LC, Douma S, van Doorn R, et al. (2008) Oncogene-induced senescence relayed by an interleukin-dependent inflammatory network. Cell 133: 1019-1031. [PubMed]

15. Rodier F, Coppe JP, Patil CK, Hoeijmakers WA, Munoz DP, et al. (2009) Persistent DNA damage signalling triggers senescence-associated inflammatory cytokine secretion. Nat Cell Biol 11: 973-979. [PubMed]

16. Lauffenburger DA, Linderman J, Berkowitz L (1987) Analysis of mammalian cell growth factor receptor dynamics. Ann N Y Acad Sci 506: 147-162. [PubMed]

17. Childs BG, Durik M, Baker DJ, van Deursen JM (2015) Cellular senescence in aging and age-related disease: from mechanisms to therapy. Nat Med 21: 1424-1435. [PubMed]

18. Lasry A, Ben-Neriah Y (2015) Senescence-associated inflammatory responses: aging and cancer perspectives. Trends Immunol 36: 217-228. [PubMed]

19. Nicolay NH, Lopez Perez R, Saffrich R, Huber PE (2015) Radio-resistant mesenchymal stem cells: mechanisms of resistance and potential implications for the clinic. Oncotarget 6: 19366-19380. [PubMed]

20. Munoz-Espin D, Canamero M, Maraver A, Gomez-Lopez G, Contreras J, et al. (2013) Programmed cell senescence during mammalian embryonic development. Cell 155: 1104-1118. [PubMed]

21. Schmitt CA, Fridman JS, Yang M, Lee S, Baranov E, et al. (2002) A senescence program controlled by $\mathrm{p} 53$ and $\mathrm{p} 16 \mathrm{INK} 4 \mathrm{a}$ contributes to the outcome of cancer therapy. Cell 109: 335-346. [PubMed]

22. Ewald JA, Desotelle JA, Wilding G, Jarrard DF (2010) Therapy-induced senescence in cancer. J Natl Cancer Inst 102: 1536-1546. [PubMed]

23. Shao L, Wang Y, Chang J, Luo Y, Meng A, et al. (2013) Hematopoietic stem cell senescence and cancer therapy-induced long-term bone marrow injury. Transl Cancer Res 2: 397-411. [PubMed]

24. Nardella C, Clohessy JG, Alimonti A, Pandolfi PP (2011) Pro-senescence therapy for cancer treatment. Nat Rev Cancer 11: 503-511. [PubMed]

25. Uccelli A, Moretta L, Pistoia V (2008) Mesenchymal stem cells in health and disease. Nat Rev Immunol 8: 726-736. [PubMed]

26. Rumman M, Dhawan J, Kassem M (2015) Concise Review: Quiescence in Adult Stem Cells: Biological Significance and Relevance to Tissue Regeneration. Stem cells 33: 2903-2912. [PubMed]

27. Niu P, Smagul A, Wang L, Sadvakas A, Sha Y, et al. (2015) Transcriptional profiling of interleukin-2-primed human adipose derived mesenchymal stem cells revealed dramatic changes in stem cells response imposed by replicative senescence. Oncotarget 6: 17938-17957. [PubMed]

28. Lunyak VV, Rosenfeld MG (2008) Epigenetic regulation of stem cell fate. Hum Mol Genet 17: R28-36. [PubMed]

29. Lopez MF, Niu P, Wang L, Vogelsang M, Gaur M, et al. (2017) Opposing activities of oncogenic MIR17HG and tumor suppressive MIR100HG clusters and their gene targets regulate replicative senescence in human adult stem cells. npj Aging and Mechanisms of Disease 3: 7. [PubMed]

30. Dominici M, Le Blanc K, Mueller I, Slaper-Cortenbach I, Marini F, et al. (2006) Minimal criteria for defining multipotent mesenchymal stromal cells. The International Society for Cellular Therapy position statement. Cytotherapy 8 : 315-317. [PubMed]

31. Lopez MF, Tollervey J, Krastins B, Garces A, Sarracino D, et al. (2012) Depletion of nuclear histone $\mathrm{H} 2 \mathrm{~A}$ variants is associated with chronic DNA damage signaling upon drug-evoked senescence of human somatic cells. Aging (Albany NY) 4: 823-842. [PubMed]

32. Feng J, Meyer CA, Wang Q, Liu JS, Shirley Liu X, et al. (2012) GFOLD: a generalized fold change for ranking differentially expressed genes from RNAseq data. Bioinformatics 28: 2782-2788. [PubMed]

33. Kuilman T, Peeper DS (2009) Senescence-messaging secretome: SMS-ing cellular stress. Nat Rev Cancer 9: 81-94. [PubMed]

34. Coppe JP, Patil CK, Rodier F, Krtolica A, Beausejour CM, et al. (2010) A humanlike senescence-associated secretory phenotype is conserved in mouse cells dependent on physiological oxygen. PLoS One 5: e9188. [PubMed]

35. Coppe JP, Desprez PY, Krtolica A, Campisi J (2010) The senescenceassociated secretory phenotype: the dark side of tumor suppression. Annu Rev Pathol 5: 99-118. [PubMed]

36. Acosta JC, Banito A, Wuestefeld T, Georgilis A, Janich P, et al. (2013) A complex secretory program orchestrated by the inflammasome controls paracrine senescence. Nat Cell Biol 15: 978-990. [PubMed]

37. Pribluda A, Elyada E, Wiener Z, Hamza H, Goldstein RE, et al. (2013) A senescence-inflammatory switch from cancer-inhibitory to cancer-promoting mechanism. Cancer Cell 24: 242-256. [PubMed]

38. Maumus M, Peyrafitte JA, D'Angelo R, Fournier-Wirth C, Bouloumie A, et al. (2011) Native human adipose stromal cells: localization, morphology and phenotype. Int J Obes (Lond) 35: 1141-1153. [PubMed]

39. Amable PR, Teixeira MV, Carias RB, Granjeiro JM, Borojevic R (2014) Gene expression and protein secretion during human mesenchymal cell differentiation into adipogenic cells. BMC Cell Biol 15: 46. [PubMed]

40. Amable PR, Teixeira MV, Carias RB, Granjeiro JM, Borojevic R (2014) Mesenchymal stromal cell proliferation, gene expression and protein production in human platelet-rich plasma-supplemented media. PLoS One 9: e104662. [PubMed]

41. Nagase H, Woessner JF Jr (1999) Matrix metalloproteinases. J Biol Chem 274 21491-21494. [PubMed]

42. Toth M, Bernardo MM, Gervasi DC, Soloway PD, Wang Z, et al. (2000) Tissue inhibitor of metalloproteinase (TIMP)-2 acts synergistically with synthetic matrix metalloproteinase (MMP) inhibitors but not with TIMP-4 to enhance the (Membrane type 1)-MMP-dependent activation of pro-MMP-2. J Biol Chem 275: 41415-41423. [PubMed]

43. Brew K, Nagase $H$ (2010) The tissue inhibitors of metalloproteinases (TIMPs): an ancient family with structural and functional diversity. Biochim Biophys Acta 1803: 55-71. [PubMed] 
Citation: Gaur M, Wang L, Amaro-Ortiz A, Dobke M, King Jordan I, et al. (2017) Acute Genotoxic Stress-Induced Senescence in Human Mesenchymal Cells Drives a Unique Composition of Senescence Messaging Secretome (SMS). J Stem Cell Res Ther 7: 396. doi: 10.4172/21577633.1000396

Page 13 of 13

44. von Mering C, Jensen LJ, Snel B, Hooper SD, Krupp M, et al. (2005) STRING: known and predicted protein-protein associations, integrated and transferred across organisms. Nucleic Acids Res 33: D433-437. [PubMed]

45. Ozcan S, Alessio N, Acar MB, Mert E, Omerli F, et al. (2016) Unbiased analysis of senescence associated secretory phenotype (SASP) to identify common components following different genotoxic stresses. Aging (Albany NY) 8: 13161329. [PubMed]

46. Chen PM, Liu KJ, Hsu PJ, Wei CF, Bai $\mathrm{CH}$, et al. (2014) Induction of immunomodulatory monocytes by human mesenchymal stem cell-derived hepatocyte growth factor through ERK1/2. J Leukoc Biol 96: 295-303. [PubMed]

47. Murphy MB, Moncivais K, Caplan Al (2013) Mesenchymal stem cells: environmentally responsive therapeutics for regenerative medicine. Exp Mol Med 45: e54. [PubMed]

48. Bai L, Lennon DP, Caplan Al, DeChant A, Hecker J, et al. (2012) Hepatocyte growth factor mediates mesenchymal stem cell-induced recovery in multiple sclerosis models. Nat Neurosci 15: 862-870. [PubMed]

49. O'Cearbhaill ED, Punchard MA, Murphy M, Barry FP, McHugh PE, et al. (2008) Response of mesenchymal stem cells to the biomechanical environment of the endothelium on a flexible tubular silicone substrate. Biomaterials 29: 16101619. [PubMed]

50. Holgate ST, Davies DE, Lackie PM, Wilson SJ, Puddicombe SM, et al. (2000) Epithelial-mesenchymal interactions in the pathogenesis of asthma. J Allergy Clin Immunol 105: 193-204. [PubMed]

51. Spees JL, Lee RH, Gregory CA (2016) Mechanisms of mesenchymal stem/ stromal cell function. Stem Cell Res Ther 7:125. [PubMed]

52. Ben-Ami E, Miller A, Berrih-Aknin S (2014) T cells from autoimmune patients display reduced sensitivity to immunoregulation by mesenchymal stem cells: role of IL-2. Autoimmun Rev 13: 187-196. [PubMed]

53. Ichim TE, Alexandrescu DT, Solano F, Lara F, Campion Rde N, et al. (2010) Mesenchymal stem cells as anti-inflammatories: implications for treatment of Duchenne muscular dystrophy. Cell Immunol 260: 75-82. [PubMed]

54. Yi T, Song SU (2012) Immunomodulatory properties of mesenchymal stem cells and their therapeutic applications. Arch Pharm Res 35: 213-221. [PubMed]

55. Bernotiene E, Palmer G, Gabay C (2006) The role of leptin in innate and adaptive immune responses. Arthritis Res Ther 8: 217. [PubMed]

56. Tian Z, Sun R, Wei H, Gao B (2002) Impaired natural killer (NK) cell activity in leptin receptor deficient mice: leptin as a critical regulator in NK cell development and activation. Biochem Biophys Res Commun 298: 297-302. [PubMed]

57. De Rosa V, Procaccini C, Cali G, Pirozzi G, Fontana S, et al. (2007) A key role of leptin in the control of regulatory T cell proliferation. Immunity 26: 241-255. [PubMed]

58. Springer TA (1994) Traffic signals for lymphocyte recirculation and leukocyte emigration: the multistep paradigm. Cell 76: 301-314. [PubMed]

59. Ley K, Tedder TF (1995) Leukocyte interactions with vascular endothelium New insights into selectin-mediated attachment and rolling. J Immunol 155 525-528. [PubMed]

60. Marlin SD, Springer TA (1987) Purified intercellular adhesion molecule-1 (ICAM-1) is a ligand for lymphocyte function-associated antigen 1 (LFA-1). Cel 51:813-819. [PubMed]

61. Wang HW, Babic AM, Mitchell HA, Liu K, Wagner DD (2005) Elevated soluble ICAM-1 levels induce immune deficiency and increase adiposity in mice. FASEB J 19: 1018-1020.

62. Chen H, Shi B, Feng X, Kong W, Chen W, et al. (2015) Leptin and NeutrophilActivating Peptide 2 Promote Mesenchymal Stem Cell Senescence Through Activation of the Phosphatidylinositol 3-Kinase/Akt Pathway in Patients With Systemic Lupus Erythematosus. Arthritis Rheumatol 67: 2383-2393. [PubMed]

63. Wajapeyee N, Serra RW, Zhu X, Mahalingam M, Green MR (2008) Oncogenic BRAF induces senescence and apoptosis through pathways mediated by the secreted protein IGFBP7. Cell 132: 363-374. [PubMed]

64. Kortlever RM, Higgins PJ, Bernards R (2006) Plasminogen activator inhibitor-1 is a critical downstream target of p53 in the induction of replicative senescence. Nat Cell Biol 8: 877-884. [PubMed]

65. Severino V, Alessio N, Farina A, Sandomenico A, Cipollaro M, et al. (2013) Insulin-like growth factor binding proteins 4 and 7 released by senescent cells promote premature senescence in mesenchymal stem cells. Cell Death Dis 4 : e911. [PubMed]

66. Berezhkovskii AM, Coppey M, Sealfon SC, Shvartsman S (2008) Cell-to-cell communication: time and length scales of ligand internalization in cultures of suspended cells. J Chem Phys 128: 225102. [PubMed]

67. Klopp AH, Gupta A, Spaeth E, Andreeff M, Marini F (2011) Concise review: Dissecting a discrepancy in the literature: do mesenchymal stem cells support or suppress tumor growth? Stem Cells 29: 11-19. [PubMed] 